Oksana Krupka, Vitaliy Smokal, Sergey Studzinsky,
Nikolay Davidenko and Angelina Biitseva

\title{
ELECTRO-OPTICAL PROPERTIES IN THIN FILMS OF NEW AZOBENZENE POLYMERS
}

\author{
Kyiv Taras Shevchenko National University \\ 60, Volodymyrska str., 01033 Kyiv, Ukraine; vitaliismokal@gmail.com
}

Received: December 06, 2013 / Revised: February 14, 2014 / Accepted: April 28, 2014

(C) Krupka O., Smokal V., Studzinsky S., Davidenko N., Biitseva A., 2015

\begin{abstract}
In this paper we report the synthesis of side chain methacrylic polymers functionalized with azobenzene chromophores. A reversible change of thin film absorption is observed when illuminating it with monochromatic, linearly polarized light under the applied external DC field. The amount of change depends on the angle between the light polarization and the DC electric field direction.
\end{abstract}

Keywords: azopolymers, Disperse Red 1 (DR1), photoisomers, electro-optical effect.

\section{Introduction}

Polymers containing azobenzene dyes or azobenzene lateral groups [1-8] are of special interest for their application as optically active media, in particular, as polarization sensitive media for applications like surface relief gratings formation [9], optical data storage [10-12], photoswitching [13], alignment of liquid crystals [14], optical elements [15]. Previous years an intensive research was devoted to the study of second order nonlinear optical (NLO) response of azobenzene containing polymer systems $[16,17]$.

The desirable properties of these materials are due to the highly efficient photoinduced trans-cis and vice versa isomerization of azobenzene moieties. This transformation is connected with the molecule volume change, associated with a change of its rotational mobility. The trans-cis isomerization process is exploited also in all-optical poling [18]. Generally, the light induces this phenomenon with frequencies lying within the chromophore absorption band, although the two-photon induced photoisomerization was also observed [19, 20].

The photoinduced polarization can be created at room temperature. It can be modified by external thermal or mechanical treatments, illumination by light, and by external electric fields.
Usually the polar orientation of chromophores is done by applying an external electric DC field. The orienting force originates from the interaction of molecule dipole moments with the applied external electric field, which tends to orient them in its direction. Therefore molecules with large dipole moments are needed. An example of such molecules presents intramolecular charge transfer (CT) ones with electron donating and electron accepting groups. The $\pi$ electron conjugated azobenzene moiety, linking donor with acceptor, serves as a charge transmitter between them. Such molecules lack also center of inversion, a property necessary to obtain second order NLO effects, such as second harmonic generation (SHG) and linear electro-optical effect. This fact is important for a proper choice of compounds designed for application in optoelectronic devices.

In this paper we report on the synthesis of novel methacrylic side chain polymers grafted with azobenzenes (Fig. 1). The linear electro-optical effect in thin films made of these polymers will be reported and discussed.

\section{Experimental}

${ }^{1} H$ NMR $(500 \mathrm{MHz})$ spectra were recorded by a "Bruker Advance DRX-500" spectrometer. Chemical shifts are in ppm from the internal standard tetramethylsilane. $U V$-Vis absorption measurements were performed at room temperature either in solutions in a quartz cell or in thin films deposited on glass substrates with a Perkin-Elmer UV/VIS/NIR Lambda 19 spectrometer. Differential Scanning Calorimetry: A Q20 model DSC (TA Instruments), with a continuous $\mathrm{N}_{2}$ purge was used to determine the glass transition temperatures $\left(T_{g}\right)$ of all polymers. Two scans were run at a heating rate of $10 \% \mathrm{~min}$ up to $473 \mathrm{~K}$, followed by a cooling to $293 \mathrm{~K}$, giving the values of $T_{g}$. 


\subsection{M aterials}

Standard distillation procedures were performed for triethylamine and THF just prior to use. 2,2'-Azobis(isobutyronitrile) (AIBN) was recrystallized twice from methanol. Methacrylic chloride was vacuum distilled, immediately before use. Methylmethacrylate (MMA) was washed with aq. $\mathrm{NaOH}$ to remove inhibitors and dried with $\mathrm{CaCl}_{2}$ under nitrogen at reduced pressure. The chromophores 4-(4-nitrophenylazo)aniline, $\mathrm{N}$-ethyl$N$-(2-hydroxyethyl)-4-(4-nitrophenylazo)aniline DR1, 4-[4-(phenylazo)-1-naphthylazo]phenol DO13, purchased from Aldrich, were purified by the double recrystallization from a methanol solution. All other reagents and solvents were commercially available and used as received. 4-(N-Ethyl-N-(2-hydroxyethyl)amino)-4'-(4nitrophenylazo)azobenzene.

4-(4-Nitrophenylazo)aniline (5 g, $20.6 \mathrm{mmol})$ was dissolved in a solution of concentrated hydrochloric acid $10 \mathrm{ml}$ and DMF $80 \mathrm{ml}$. The reaction mixture was cooled down in an ice-water bath to $273 \mathrm{~K}$ and stirred for $15 \mathrm{~min}$. Then a solution of sodium nitrite $(1.45 \mathrm{~g}, 21 \mathrm{mmol})$ in $5 \mathrm{ml}$ of water was dropwise added. The reaction mixture was stirred for $2 \mathrm{~h}$ at $273 \mathrm{~K}$ and then the N-ethyl-N-(2hydroxyethyl)aniline $(3.5 \mathrm{~g}, 21 \mathrm{mmol})$ in $15 \mathrm{ml}$ of acetic acid was dropwise added. After stirring at 273-278 K for $5 \mathrm{~h}$ and $12 \mathrm{~h}$ at room temperature a large amount of dark precipitate was formed. The precipitate was collected by filtration and then washed with saturated sodium bicarbonate solution and dried. The crude product was purified by column chromatography on silica gel (toluene : acetone, 1:1.5), followed by recrystallization from THF : hexane and was obtained as dark purple crystals m.p. $498 \mathrm{~K}, 62 \%$.

${ }^{1} \mathrm{H}$ NMR (500 MHz, DMSO-d6): $\delta 8.46(\mathrm{~d}, 2 \mathrm{H}, \mathrm{Ar}-$ H), $8.00(\mathrm{~d}, 2 \mathrm{H}, \mathrm{Ar}-\mathbf{H}), 8.12(\mathrm{~d}, 4 \mathrm{H}, \mathrm{Ar}-\mathbf{H}), 7.85(\mathrm{~d}, 2 \mathrm{H}$, Ar-H), 6.90 (d, 2H, Ar-H), 4.85 (t, 1H, OH), 3.55-3.65 $\left(\mathrm{m}, 6 \mathrm{H},-\mathrm{CH}_{2}-\right), 1.18\left(\mathrm{~s}, 3 \mathrm{H},-\mathrm{CH}_{3}\right)$. UV-Vis (THF): $\lambda=346,520 \mathrm{~nm}$.

4-((2-Methacryloyloxyethyl)ethylamino $)-4-$ nitroazobenzene (M1).

Azomonomer was synthesized in the same way as reported in [21]. The solid was recrystallized from methanol. Dark red crystals were obtained with m.p. $356 \mathrm{~K}$ and the yield of $80 \%$.

${ }^{1} \mathrm{H}$ NMR (500 MHz, $\left.\mathrm{CDCl}_{3}\right): \delta 8.35(\mathrm{~d}, 2 \mathrm{H}, \mathrm{Ar}-\mathbf{H})$, 7.92 (t, 4H, Ar-H), 6.85 (d, 2H, Ar-H), 6.1 (s, 1H, CH $\mathbf{H}_{2}$, $5.6\left(\mathrm{~s}, 1 \mathrm{H}, \mathrm{CH}_{2}\right), 4.38\left(\mathrm{~m}, 2 \mathrm{H}, \mathrm{OCH}_{2}\right), 3.75(\mathrm{~m}, 2 \mathrm{H}$, $\left.\mathrm{NCH}_{2}\right), 3.56\left(\mathrm{~m}, 2 \mathrm{H}, \mathrm{NCH}_{2}\right), 1.94\left(\mathrm{~s}, 3 \mathrm{H}, \mathrm{CH}_{3}\right), 1.24(\mathrm{~m}$, $\left.3 \mathrm{H}, \mathrm{CH}_{3}\right)$. UV-Vis (THF): $\lambda=475 \mathrm{~nm}$.

4-((2-Methacryloyloxy)-4'-(4-(phenylazo)-1naphthylazo)benzene (M2).

A solution of 4-[4-(phenylazo)-1-naphthylazo]phenol $(1.5 \mathrm{~g}, 4.2 \mathrm{mmol})$ and triethylamine $(0.64 \mathrm{~g}$,
$6.3 \mathrm{mmol}$ ) was dissolved in THF $(40 \mathrm{ml})$. The solution was kept in an ice bath for $10 \mathrm{~min}$. Then a solution of distilled methacryloyl chloride $(0.66 \mathrm{~g}, 6.3 \mathrm{mmol})$ in THF $(10 \mathrm{ml})$ was added slowly to the reaction mixture. After the addition of methacryloyl chloride, the solution was stirred for $12 \mathrm{~h}$ at ambient temperature. The solvent was removed by rotary evaporation and the residue was washed with a solution of sodium carbonate $(0.8 \mathrm{~g})$ in water $(40 \mathrm{ml})$. After removing the solvent, the resulting material was purified by column chromatography (silica gel, ethyl acetate/hexane 1/8). A red solid residue was obtained with the yield of $75 \%$, m.p. $363 \mathrm{~K}$.

${ }^{1} \mathrm{H}$ NMR (500 MHz, DMSO-d6): $\delta$ 9.01-8.98 (m, 2H, naphthalene), 8.14 (d, 2H, Ar-H), 8.05 (d, 2H, Ar-H), 7.92 (s, 2H, naphthalene), 7.85 (d, 2H, Ar-H), 7.78-7.81 (m, 2H, naphthalene), 7.63-7.58 (m, 3H, Ar-H), 6.35 (s, $1 \mathrm{H}, \mathrm{CH}_{2}$ ), 5.9 (s, 1H, CH $\left.\mathbf{H}_{2}\right), 2.07$ (s, 3H, CH 3 ). UV-Vis (THF): $\lambda=325,428 \mathrm{~nm}$.

4-((2-Methacryloyloxyethyl)ethylamino)-4'-(4-

nitrophenylazo)azobenzene (M3).

Azomonomer M3 was synthesized in the same way as azomonomer M2. Dark purple crystals were obtained: yield $60 \%$; m. p. $433 \mathrm{~K}$.

${ }^{1} \mathrm{H}$ NMR $\left(500 \mathrm{MHz}, \mathrm{CDCl}_{3}\right): \delta 8.40(\mathrm{~d}, 2 \mathrm{H}, \mathrm{Ar}-\mathbf{H})$, 8.12-7.92 (m, 8H, Ar-H), 6.85 (d, 2H, Ar-H), 6.12 (s, 1H, $\left.\mathrm{CH}_{2}\right), 5.61\left(\mathrm{~s}, 1 \mathrm{H}, \mathrm{CH}_{2}\right), 4.38\left(\mathrm{t}, 2 \mathrm{H}, \mathrm{OCH}_{2}\right), 3.75(\mathrm{t}, 2 \mathrm{H}$, $\mathrm{NCH}_{2}$ ), 3.55 (q, 2H, $\mathrm{NCH}_{2} \mathrm{CH}_{3}$ ), 1.97 (s, 3H, CH${ }_{3}$ ), 1.28 (s, 3H, $\mathrm{CH}_{3}$ ). UV-Vis (THF): $\lambda=340,502 \mathrm{~nm}$.
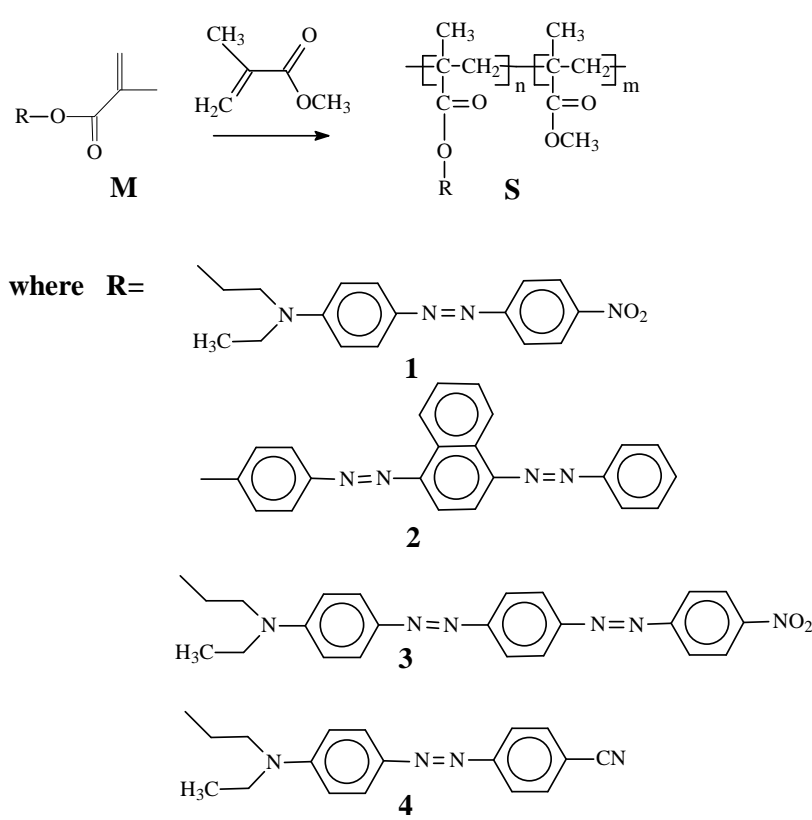

Fig. 1. Chemical structures of the studied azopolymers 


\section{4'-[(2-Methacryloyloxyethyl)ethylamino]-4- cyanoazobenzene (M4).}

M4 was obtained as described for M2: red solid residue, yield: $87 \%$. ${ }^{1} \mathrm{H}$ NMR $\left(500 \mathrm{MHz}, \mathrm{CDCl}_{3}\right): \delta 7.89$, 7.87 (d, 4H, Ar-H), 7.75, 7.73 (d, 2H, Ar-H), 6.82, 6.8 (d, $2 \mathrm{H}, \operatorname{Ar}-\mathbf{H}), 6.1\left(\mathrm{~s}, 1 \mathrm{H}, \mathbf{C H}_{2}\right), 5.6\left(\mathrm{~s}, 1 \mathrm{H}, \mathrm{CH}_{2}\right), 4.36(\mathrm{~m}$, $\left.2 \mathrm{H}, \mathrm{OCH}_{2}\right), 3.7\left(\mathrm{~m}, 2 \mathrm{H}, \mathrm{NCH}_{2}\right), 3.55\left(\mathrm{~m}, 2 \mathrm{H}, \mathrm{NCH}_{2}\right)$, $1.94\left(\mathrm{~s}, 3 \mathrm{H}, \mathrm{CH}_{3}\right), 1.25$ (m, 3H, CH $\mathbf{H}_{3}$ ). UV-Vis (THF): $\lambda=250,450 \mathrm{~nm}$.

\subsection{Polymerization}

Polymers were synthesized by free-radical polymerization. The polymerization was carried out in $10 \mathrm{wt} \%$ toluene solution of M1 and Methylmethacrylate (MMA) with monomers initial mole ratios 1:3. The polymerization was conducted using AIBN as a free radical initiator ( $1 \mathrm{wt} \%$ of monomer) at $353 \mathrm{~K}$ for $35 \mathrm{~h}$ in argon atmosphere. Previously the initial mixture was degassed with repeated freeze-pump-taw cycles. Pouring the reaction mixture into methanol stopped the polymerization. This procedure was repeated several times to ensure removal of unreacted methacrylic monomers and finally the polymer $\mathbf{S 1}$ was dried under vacuum at $323 \mathrm{~K}$ overnight. Copolymerization of M2 with MMA, M3 with MMA, and M4 with MMA was conducted by the same methods in DMF, 1,4-dioxane, and toluene solution, respectively. The copolymerization ratios in the corresponding polymers were calculated on the basis of the integrated peak areas of ${ }^{1} \mathrm{H}$ NMR spectra in DMSO- $d_{6}$ for $\mathbf{S 1}, \mathbf{S 3}, \mathbf{S 4}$ and in pyridine- $d_{5}$ for $\mathbf{S 2}$. The glass transition temperatures were measured by differential scanning calorimetry to be $398,383,413$ and $393 \mathrm{~K}$ for the copolymers $\mathbf{S 1}, \mathbf{S 2}, \mathbf{S 3}$, and $\mathbf{S 4}$, respectively.

\subsection{Thin Films Processing}

Thin films of S1, S2, S3, and S4 were obtained by drop casting of filtered solutions through a $0.4 \mu \mathrm{m}$ pore size nylon syringe filter on conducting layer $\mathrm{SnO}_{2}: \mathrm{In}_{2} \mathrm{O}_{3}$ of glass slides. We used dichloroethane as solvent for the quality of thin film formation. The same polymer concentration of $56 \mathrm{~g} / \mathrm{l}$ was used. Immediately after the deposition, the films were cured in a vacuum drying chamber at $323 \mathrm{~K}$ for $180 \mathrm{~min}$ in order to eliminate any remaining solvent.

\subsection{Electro-Optical Measurements}

Optical absorption spectra of the studied polymer films were measured in the wavelength range 350-900 nm. Their electro-optical properties were determined by measuring the intensity of monochromatic light induced through electro-optical cell with the sample in the area of external electric field. The value $\delta I_{E}$ is calculated according to the formula:

$$
\delta I_{E}=\frac{I_{E}-I_{0}}{I_{0}}
$$

where $I_{0}$ and $I_{E}$ are intensities of the monochromatic probing beam in the absence $\left(I_{0}\right)$ and the presence $\left(I_{E}\right)$ of the external field induced relative electro-optical cell, respectively.

Polarized and unpolarized beams were used for sample illumination. In the first case the sample was placed between two polarizers. Using a special device an electric field of $E=1 \cdot 10^{8} \mathrm{~V} / \mathrm{m}$ was produced by corona discharge. The transmission variations $\delta I_{E}$ measurements were done in function of angle $\theta$ between two polarizers, probing beam wavelength $\lambda$, sample illumination time $t$. The measurements were done also at the wavelengths lying in the tail of absorption band. All experiments were carried out at the temperature of $T=293 \mathrm{~K}$. At this temperature the light depolarizing effect of $\mathrm{SnO}_{2}: \mathrm{In}_{2} \mathrm{O}_{3}$ layer is negligible [22].

\section{Results and Discussion}

The 4-(N-ethyl-N-(2-hydroxyethyl)amino)-4-cyanoazobenzene and 4-(N-ethyl-N-(2-hydroxyethyl)amino)4'-(4-nitrophenylazo)azobenzene molecules were prepared by coupling with the diazonium salt of 4-aminobenzonitrile or 4-(4-nitrophenylazo)aniline and further with 2-( $N$-ethylanilino)ethanol according to the procedure published previously [21]. The azobenzene methacrylate monomers were synthesized by reaction of azobenzene alcohols with methacryloyl chloride in the presence of triethylamine as nucleophilic catalyst and hydrochloric acid acceptor. The polymers were synthesized by radical polymerization using AIBN as radical initiator.

The chemical structures of obtained polymers were confirmed by ${ }^{1} \mathrm{H}$ NMR spectra. The compositions of the copolymers were well controlled by the initial ratio of the azobenzene monomers and MMA (1:3).

The absorption spectra of the investigated polymer films are shown in Fig. 2. Over the visible range, the absorption is conditioned by photoexcitation of azobenzene chromophore groups, and corresponds to the $n-\pi^{*}$ and $\pi-\pi^{*}$ electronic transitions of azobenzene polymers [13]. The bathochromic shift observed in the series S1-S4 is caused by an increase of the chromophore dipole moment. The electron-donor and electron-acceptor substituents in the synthesized polymers increase the charge transfer character of the $\pi^{-} \pi^{*}$ transition and consequently a red shift of $\pi^{-} \pi^{*}$ band. Therefore changing the strength of electron-donor and electronacceptor substituents leads to lowering of the energy of excited states [23]. 


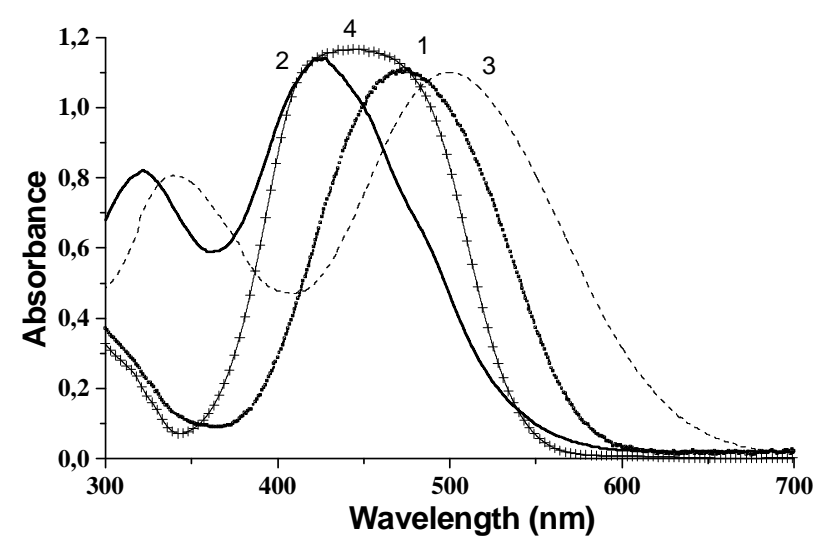

Fig. 2. Thin film absorption spectra of S1 (1), S2 (2), S3 (3) and S4 (4) polymers

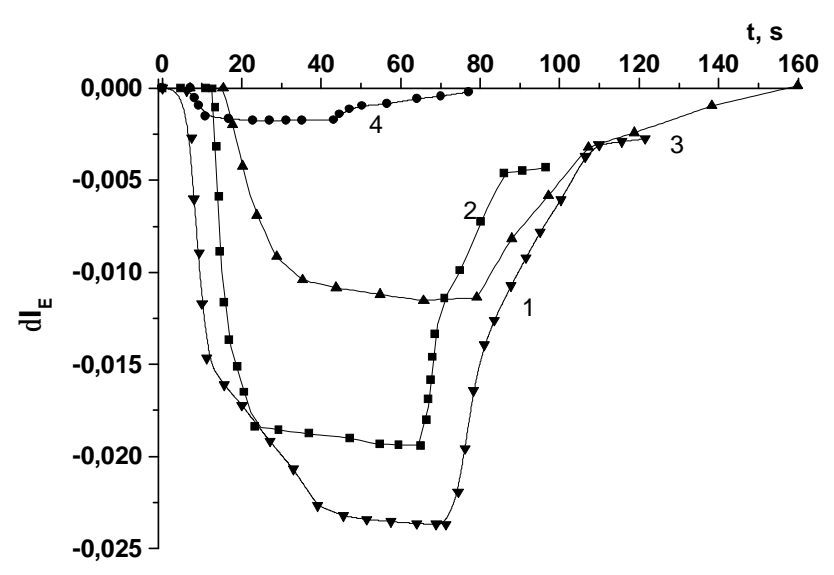

Fig. 3. Dependencies of $\delta I_{E}$ on time $t$ after application of the external electric field and its switching off after 50-60 s measured for $\theta=\pi / 2$ and $\lambda=610 \mathrm{~nm}$ in the samples $\mathrm{S} 1$ (1), S2 (2), S3 (3), and S4 (4). The samples were preliminarily illuminated with linearly polarized light $(\lambda<550 \mathrm{~nm})$ for $60 \mathrm{~min}$

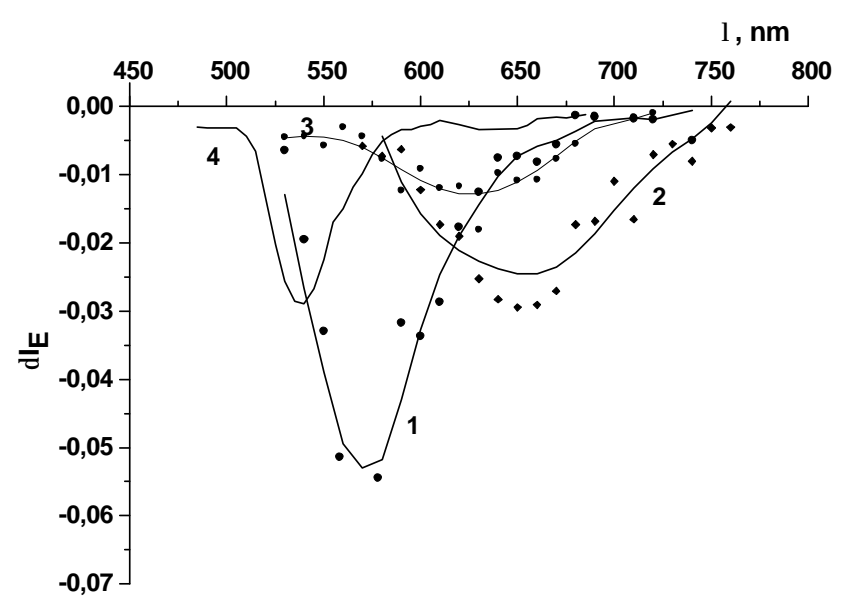

Fig. 4. Dependencies of $\delta I_{E}$ on $\lambda$ measured for $\theta=\pi / 2$ in the samples S1 (1), S2 (2), S3 (3), and S4 (4) after their previous illumination with linearly polarized light $<550 \mathrm{~nm}$ for $60 \mathrm{~min}$
The intensity of polarized light passing the samples with investigated polymer film preliminarily illuminated by a linearly polarized light decreases (Fig. 3) after the application of external electric field. It returns to its initial value when the electric field is switched off. It is well known from the studies done at room temperature for polymers similar to the presently investigated that the trans-state of azobenzene chromophore groups is predominant before illumination with linearly polarized light. Illumination of these polymers with linearly polarized light induces polarization due to the changes of trans- and cis-isomers of the azobenzene groups. The induced orientations of the electric dipole moments of trans- and cis-isomers of the azobenzene chromophores do not coincide. Therefore, the modification of the absorption of polarized light by isomers of azobenzene chromophores in polymers when an external electric field is applied (Fig. 3) is caused by rotation of electric dipole moments of azobenzene groups towards its direction. The observed changes are shown in Fig. 3, where the experimental dependencies of the kinetics of light intensity changes from $I_{0}$ to $I_{E}$ are displayed.

The experimental wavelength dependencies of $\delta I_{E}$ after quite a long illumination of the samples with polarized light with wavelength $\lambda<550 \mathrm{~nm}$ are shown in Fig. $4(\theta=\pi / 2)$.

It should be noted that after long illumination of the samples in DC field with linearly polarized light, the light transmission gains strength within the long wave range of polymer absorption spectra. In the investigated polymers samples, the observed photoinduced optical anisotropy is a result of illumination with a linearly polarized light. In films S1, S2, S4, and S3 external electric field aligns the dipoles along its direction. In films S1 and S4, due to the larger depolarization, thus larger dispersion of light polarization, the interaction of azobenzene dipoles with the applied field leads to a larger negative value of $\delta I_{E}$. The values of $\delta I_{E}$ increase in the range S1, S2, S4, S3. This peculiarity is caused, probably, by the change of dipole moment of azobenzene chromophore in S1, S2, S3, S4 series.

\section{Conclusions}

In thin films of the investigated polymers the photoinduced optical anisotropy after long-time illumination of the samples with linearly polarized light was observed. The electro-optical properties of thin films after their preliminary illumination with linearly polarized light were most pronounced within the long wave range of absorption spectra. In these media, the influence of a DC external electric field on the light transmission is attributed to displacement of the azobenzene groups from 
their equilibrium state under its action. The presence of the electron donating and electron accepting groups leads to an increase of the dipole moment of azobenzene chromophore. It results in larger interaction energy with the applied electric field and increased rotational mobility of azobenzene dipole moment. From the obtained and presented here results one can conclude that thin films of azobenzene polymers can be considered as attractive for applications requiring sensitivity to external electromagnetic stimuli, such as electro-optical light intensity modulators for optical signal transmission or polarization holography [14, 24].

\section{Acknowledgments}

The authors would like to express their thanks to the Ministry of Education and Science of Ukraine for supporting this research, program № 2201250.

\section{References}

[1] Burland D., Miller R. and Walsh C.: Chem. Rev., 1994, 94, 31.

[2] Ribierre J., Cheval G., Huber F. et al.: J. Appl. Phys., 2002, 91, 1710 .

[3] Yesodha S., Pillai C. and Tsutsumi N.: Prog. Polym. Sci., 2004, 29, 45 .

[4] Hampsch H., Yang J., Wong G. and Torkelson J.: Macromolecules, 1988, 21, 526.

[5] Andruzzi L., Altomare A., Ciardelli F. et al.: Macromolecules, 1999, 32, 448.

[6] Zhou X., Ren H., Chen C. and Wang M.: J. Appl. Polym. Sci., 1999, 73, 1913.

[7] Lebedeva G., Ivanova V., Ivanov S. et al.: Phys. Solid State, 2004, 46, 569.

[8] Loucif-Saibi R., Nakatani K., Delaire J. et al.: Chem. Mater., 1993, 5, 229.

[9] Atassi Y., Chauvin J., Delaire J. et al.: Pure \& Appl. Chem., 1998, 70, 2157.

[10] Kawata S. and Kawata Y.: Chem. Rev., 2000, 100, 1777.
[11] Natansohn A. and Rochon P.: Adv. Mater., 1999, 11, 1387.

[12] Gindre D., Boeglin A., Fort A. et al.: Opt. Express, 2006, 14, 9896.

[13] Czaplicki R., Krupka O., Essaidi Z. et al.: Opt. Express, 2007, 15, 15268 .

[14] Eaton D.: Science, 1991, 253, 281.

[15] Sekkat Z. and Knoll W.: Photoreactive Organic Thin Films. Academic press, New York 2002.

[16] Nahata A., Shan J., Yardley J. and Wu C.: J. Opt. Soc. Am. B, 1993, 10, 1553.

[17] Singer K., Kuzyk M. and Sohn J.: J. Opt. Soc. Am. B, 1987, 4, 968.

[18] Charra F., Kajzar F., Nunzi J. et al.: Optics Lett., 1993, 18, 941.

[19] Correa D., Cardoso M., Goncalves V. et al.: Polymer, 2008, 49, 1562.

[20] Kajzar F., Charra F., Nunzi J. et al.: Third Order Nonlinear Optical Properties of Functionalized Polymers [in:] P. Prasad (Ed.), Frontiers of Polymers and Advanced Materials. Plenum Press, New York 1994.

[21] El Ouazzani H., Iliopoulos K., Pranaitis M. et al.: J. Phys. Chem., 2011, 115, 1944.

[22] Davidenko N., Pavlov V., Chuprina N. et al.: J. Appl. Phys., 2006, 100, 023111-3.

[23] Wu Y., Natansohn A. and Rochon P.: Macromolecules, 2001, 34, 7822 .

[24] Ono H. and Kawatsuki N.: Adv. in Techn. of Mat. and Mat. Proc., 2005, 7, 9.

\section{ЕЛЕКТРООПТИЧІ ВЛАСТИВОСТІ В ТОНКИХ ПЛІВКАХ НОВИХ АЗОБЕНЗОЛЬНИХ ПОЛІМЕРІВ}

Анотація. Синтезовано ряд азобензолвмісних мономерів та представлений синтез метакрильних полімерів з азобензольними хромофорами в бічних ланцюгах. Досліджено фотохімічні та електрооптичні властивості синтезованих полімерів. Будову мономерів $і$ полімерів доведено методом ПМР спектроскопії. Реверсивна зміна поглинання в попередньо опромінених монохроматичним лінійно поляризованим світлом тонких плівках спостерігалася під впливом зовнішнього електричного поля.

Ключові слова: азополімери, фотоізомери, електрооптичний ефект. 
